\title{
Price Stability and the Case for Flexible Exchange Rates
}

\author{
Nicolas A. Cuche-Curti • Harris Dellas • \\ Jean-Marc Natal
}

Published online: 18 December 2009

(C) Springer Science+Business Media, LLC 2009

\begin{abstract}
We revisit Friedman's case for flexible exchange rates in a small open economy with several distortions and rigidities and a variety of domestic and external shocks. We find that, for external shocks, the flexible exchange rate regime outperforms the fixed regime independent of the source of domestic nominal rigidities provided that the monetary authorities pursue a policy of strict inflation targeting. For domestic supply shocks, a joint policy of a flexible exchange rate and strict inflation targeting fares well when the main source of nominal rigidities is in the domestic goods markets, but not if rigidities arise in the labor markets.
\end{abstract}

N. A. Cuche-Curti · J.-M. Natal

Swiss National Bank, SNB, P.O. Box, 8022 Zurich, Switzerland

N. A. Cuche-Curti

e-mail: nicolas.cuche-curti@snb.ch

J.-M. Natal

e-mail: jean-marc.natal@snb.ch

N. A. Cuche-Curti

University of St.Gallen, St. Gallen, Switzerland

H. Dellas $(\bowtie)$

Department of Economics, University of Bern,

Schanzeneckstr. 1, 3012 Bern, Switzerland

e-mail: harris.dellas@vwi.unibe.ch

H. Dellas

CEPR, Schanzeneckstr. 1, 3012 Bern, Switzerland 
Keywords Exchange rate regimes $\cdot$ Monetary policy $\cdot$ Nominal rigidities • Price rigidities

JEL Classification $\mathrm{E} 32 \cdot \mathrm{E} 52 \cdot \mathrm{F} 33 \cdot \mathrm{F} 42$

\section{Introduction}

Following the seminal contribution of Friedman (1953), the study of the properties of alternative, credible, exchange rate regimes has gone through two distinct phases. The first one is associated with the Mundell-Fleming model and its rational expectations offsprings of the 70 s and 80 s. The second one with the newly developed New Keynesian model.

Models of the first phase exhibit the following features: a) the reliance on aggregate, ad hoc specifications; b) the use of macroeconomic stability (typically, output and inflation) as the criterion for the evaluation of alternative regimes; and c) the assumption that monetary policy is conducted according to a simple targeting procedure (typically, money or interest rate targeting). The main results that emerged from this literature are twofold. First, floating exchange rates are useful in bringing about relative price adjustment when nominal goods prices are sluggish (Friedman 1953). Second, the targeting of the exchange rate contributes to greater macroeconomic stability when domestic money demand shocks are the main source of volatility. For dominant domestic fiscal shocks, a flexible system fares better (for reasons related to Poole's (1970), analysis of the implications of alternative central bank operating procedures).

The second phase has adopted an approach that deviates from all of the above assumptions. ${ }^{1}$ The models have clear microfoundations. Consequently, it is possible to employ explicit utility-based criteria for the evaluation of welfare under alternative exchange rate systems. Moreover, the analysis of the properties of alternative regimes has been undertaken predominantly under the assumption that monetary policy is conducted optimally. Coupled with the assumption that policymakers are omniscient and omnipotent, the last assumption has introduced a strong bias in favor of the flexible exchange rate system, as this regime does not interfere with the desired actions of the monetary authorities. Consequently, with a few exceptions that arise in relatively stylized environments with pricing-to-market and buyer's currency denomination of trade, a flexible exchange rate system tends to perform relatively better.

Nevertheless, the second approach has some important limitations that undermine the strength of its case for flexible rates. First, its ranking of regimes

\footnotetext{
${ }^{1}$ Main examples are: Canzoneri et al. (2003), Collard and Dellas (2002), Duarte (2003), Kollmann (2002), Ohanian and Stockman (1994), and Pappa (2004).
} 
is conditional on the ability of the monetary authorities to design monetary policy optimally, rather than rely on some simple rules. This may be theoretically interesting but seems to be of limited practical importance as it requires a great deal of detailed information regarding the structure of the economy and the shocks. The current debates in macroeconomics leave no doubt that such knowledge is not available. Second, most of the analysis is conducted in highly stylized environments in which either the non-monetary distortions have been eliminated through non-monetary instruments or are constant. While it is legitimate to argue that one should not let real, as opposed to nominal, frictions shape the properties of monetary policy, the matter of fact is that such distortions are present in actual economies and cannot be ignored in the analysis of the consequences of alternative monetary policies. Third, a limited number of domestic and foreign shocks is considered. Finally, most of the literature on the optimal choice of the exchange rate regime has looked at large countries. The case of small open economies has not been scrutinized sufficiently.

The objective of the present paper is to undertake a more general and practically more relevant treatment of the choice of the exchange rate regime. ${ }^{2}$ We employ a small open economy, that is characterized by a variety of real and nominal frictions, and compare exchange rate systems under simple monetary policy rules that do not strain the information capabilities of the policymakers. ${ }^{3}$ In particular, we allow for nominal frictions-both price and wage rigidities, a monetary distortion, real distortions, i.e. imperfect competition in both intermediate goods (whether domestically produced or imported) and labor markets, and active monetary policies that stabilize output around its trend rather than the flexible price equilibrium. This last feature is also related to the information capabilities of the monetary authorities. We carry out utilitybased evaluations using a second-order approximation to the decision rules in order to allow for a more accurate approximation to welfare.

Our analysis offers qualified support to Friedman's case for flexible exchange rates. First, while the flexible exchange rate system outperforms a peg for all types of external shocks independent of the source of nominal rigidities, this superiority only prevails when the monetary authorities adhere to strict inflation targeting. Were they to follow a looser inflation targeting procedure (for instance, the one prescribed by the standard Henderson-McKibbin-Taylor (HMT) rule), a fixed regime would often fare better. Second, in the case of domestic supply shocks, strict inflation targeting is not sufficient to support the flexible exchange rate system. It is also necessary that the main source of

\footnotetext{
${ }^{2}$ We restrict attention to a perfectly flexible and a perfectly fixed regime. This is not only in for reasons of comparability with the literature but also because the intermediate case of a managed float (which can be easily accommodated) would not bring any new insights to our analysis. Some form of managed floating would always weakly dominate the considered extreme cases.

${ }^{3}$ Dellas (2006), addresses more explicitly the informational limitations involved in the conduct of monetary policy.
} 
nominal rigidities is in the domestic goods market. Were nominal rigidities more pronounced in the labor markets, then a fixed regime would give rise to higher welfare. Our findings thus suggest that the choice of the exchange rate regime must be made dependent on three important characteristics of the economic environment: the type of nominal rigidity, the relative importance of alternative sources of macroeconomic volatility, and the assiduity of the monetary authorities in targeting inflation.

The rest of the paper is organized as follows. Sections 2 and 3 present the model and its calibration. Section 4 contains a description of the main experiments run and results obtained. Section 5 concludes.

\section{The model}

The model consists of a small open economy and the rest of the world. There are two different types of firms operating in the home economy. The first type produces non-traded final goods and the second type produces domestically intermediate goods that can be traded.

\subsection{The final sector firms}

Following Backus et al. (1995), we assume that the domestic final good $y$ is produced by perfectly competitive domestic firms by combining domestic $\left(x^{\mathrm{D}}\right)$ and imported $\left(x^{\mathrm{M}}\right)$ bundles of intermediate goods. The final good can be used for domestic private consumption and investment purposes. Its production is described by the following CES function

$$
y_{t}=\left(\omega^{1-\rho} x_{t}^{\mathrm{D} \rho}+(1-\omega)^{1-\rho} x_{t}^{\mathrm{M} \rho}\right)^{\frac{1}{\rho}}
$$

where $\omega \in[0,1]$ determines trade share and $\rho \in[-\infty, 1]$ determines trade elasticity.

Minimizing total expenditures, $P_{x t} x_{t}^{\mathrm{D}}+P_{m t} x_{t}^{\mathrm{M}}$, where $P_{x}$ and $P_{m}$ denote the price of, respectively, the domestic and the foreign bundle of goods, we obtain the demand functions ${ }^{4}$

$$
x_{t}^{\mathrm{D}}=\left(\frac{P_{x t}}{P_{t}}\right)^{\frac{1}{\rho-1}} \omega y_{t} \quad \text { and } \quad x_{t}^{\mathrm{M}}=\left(\frac{P_{m t}}{P_{t}}\right)^{\frac{1}{\rho-1}}(1-\omega) y_{t} .
$$

$P$ is the general price index

$$
P_{t}=\left(\omega P_{x t}^{\frac{\rho}{\rho-1}}+(1-\omega) P_{m t}^{\frac{\rho}{\rho-1}}\right)^{\frac{\rho-1}{\rho}}
$$

\footnotetext{
${ }^{4} \mathrm{In}$ the foreign economy, indexed by $\mathrm{F}$, the demand for the domestic good is $x_{t}^{\mathrm{F}}=$ $\left(\left(P_{x t} / s_{t}\right) / P_{t}^{\star}\right)^{\frac{1}{\rho-1}}\left(1-\omega^{\star}\right) y_{t}^{\star}$, where $s$ is the nominal exchange rate, $P^{\star}$ is the foreign currency general price index, and $y^{\star}$ the foreign output. Variables with a star denote world variables.
} 
The bundles of goods $x^{\mathrm{D}}$ and $x^{\mathrm{M}}$ are themselves combinations of, respectively, the domestic and foreign intermediate goods produced by a unit mass continuum of firms, indexed by $i \in[0,1]$, according to

$$
x_{t}^{\mathrm{D}}=\left(\int_{0}^{1} x_{t}^{\mathrm{D}}(i)^{\theta} \mathrm{d} i\right)^{\frac{1}{\theta}} \quad \text { and } \quad x_{t}^{\mathrm{M}}=\left(\int_{0}^{1} x_{t}^{\mathrm{M}}(i)^{\theta} \mathrm{d} i\right)^{\frac{1}{\theta}}
$$

where $\theta \in] 0,1]$. Note that $\rho$ determines the elasticity of substitution between the foreign and the domestic bundle of goods, while $\theta$ determines the elasticity of substitution between goods within the domestic and foreign bundles.

Minimizing total expenditures, $\int_{0}^{1}\left(P_{x t}(i) x_{t}^{\mathrm{D}}(i)+P_{m t}(i) x_{t}^{\mathrm{M}}(i)\right) \mathrm{d} i$, yields demand functions

$$
x_{t}^{\mathrm{D}}(i)=\left(\frac{P_{x t}(i)}{P_{x t}}\right)^{\frac{1}{\theta-1}} x_{t}^{\mathrm{D}} \quad \text { and } \quad x_{t}^{\mathrm{M}}(i)=\left(\frac{P_{m t}(i)}{P_{m t}}\right)^{\frac{1}{\theta-1}} x_{t}^{\mathrm{M}}
$$

where price subindexes are

$$
P_{x t}=\left(\int_{0}^{1} P_{x t}(i)^{\frac{\theta}{\theta-1}} \mathrm{~d} i\right)^{\frac{\theta-1}{\theta}} \quad \text { and } \quad P_{m t}=\left(\int_{0}^{1} P_{m t}(i)^{\frac{\theta}{\theta-1}} \mathrm{~d} i\right)^{\frac{\theta-1}{\theta}} .
$$

\subsection{The intermediate goods firms}

Each intermediate firm $i$ produces an intermediate good $x(i)$ using physical capital $k(i)$ and labor $h(i)$ according to a constant return-to-scale technology $\left(\alpha_{k}, \alpha_{h} \in[0,1], \alpha_{k}+\alpha_{h}=1\right)$ represented by the production function

$$
x_{t}(i)=\mathcal{A}_{t} k_{t}(i)^{\alpha_{k}} h_{t}(i)^{\alpha_{h}}
$$

where $\mathcal{A}$ is an exogenous stationary stochastic technological shock, whose properties are defined in the next section.

Minimizing total labor expenditures, $\int_{0}^{1} W_{t}(j) h_{t}(i, j) \mathrm{d} j$, leads to the following demand for labor of type $j$, provided by the households, by firm $i$

$$
h_{t}(i, j)=\left(\frac{W_{t}(j)}{W_{t}}\right)^{\frac{1}{v-1}} h_{t}(i)
$$

where the aggregate wage level is given by

$$
W_{t}=\left(\int_{0}^{1} W_{t}(j)^{\frac{\vartheta}{\vartheta-1}} \mathrm{~d} j\right)^{\frac{\vartheta-1}{\vartheta}}
$$

and labor demand by firm $i h(i)$ takes the form

$$
h_{t}(i)=\left(\int_{0}^{1} h_{t}(i, j)^{\vartheta} \mathrm{d} j\right)^{\frac{1}{\vartheta}} .
$$

Assuming that each firm $i$ operates under perfect competition in the input markets, it determines its production plan so as to minimize its total cost, 
$W_{t} h_{t}(i)+P_{t} z_{t} k_{t}(i), z$ being the real cost of capital, subject to the production function (7). Using the first-order optimal conditions, the input demand functions are given by

$$
z_{t} k_{t}(i)=\alpha_{k} \psi_{t} x_{t}(i) \quad \text { and } \quad\left(W_{t} / P_{t}\right) h_{t}(i)=\alpha_{h} \psi_{t} x_{t}(i)
$$

where the real marginal cost is given by $\psi_{t}=\frac{z_{t}^{\alpha_{k}}\left(W_{t} / P_{t}\right)^{\alpha_{h}}}{\mathcal{A}_{t} \varsigma}$ using $\varsigma=\alpha_{k}^{\alpha_{k}} \alpha_{h}^{\alpha_{h}}$.

Intermediate goods producers are monopolistically competitive. Therefore, they set prices for the good they produce. It is assumed that they face an adjustment cost when they change their prices. The profit maximization problem, with discount factors ${ }^{5} D_{t, t}=1$ and $D_{t, t+n}=\beta^{n} \frac{\Lambda_{t+n}(j)}{\Lambda_{t}(j)}$, is given by $\max _{P_{x t}(i)}\left\{\mathbb{E}_{t} \sum_{n=0}^{\infty} D_{t, t+n} \Pi_{x t+n}(i)\right\}$ using the profit function $\Pi_{x t}(i)=$ $\left(P_{x t}(i)-P_{t} \psi_{t}\right) x_{t}(i)-\frac{\xi_{x}}{2}\left(\frac{P_{x t}(i)}{P_{x t-1}(i)}-\pi_{x}\right)^{2} P_{t} y_{t}$. The last large element represents the cost of changing prices expressed in units of the final good $y$. Variables without any time subscript indicate steady-state values and $\pi_{x}$ is the steadystate rate of domestic price inflation. The first-order optimal condition with regard to the choice of price, $P_{x t}(i)$, can be expressed as follows

$$
P_{x t}(i)=\frac{1}{\theta}\left(P_{t} \psi_{t}+\frac{\theta-1}{x_{t}(i)}\left[\begin{array}{c}
\frac{P_{x t}(i)}{P_{x t-1}(i)} \xi_{x}\left(\frac{P_{x t}(i)}{P_{x t-1}(i)}-\pi_{x}\right) P_{t} y_{t}- \\
\mathbb{E}_{t} D_{t, t+1} \frac{P_{x t+1}(i)}{P_{x t}(i)} \xi_{x}\left(\frac{P_{x t+1}(i)}{P_{x t}(i)}-\pi_{x}\right) P_{t+1} y_{t+1}
\end{array}\right]\right) .
$$

Concerning the importers, we assume a similar setup as the one described for the domestic producers, where we use $s_{t} P_{t}^{\star}$ instead of a nominal marginal cost expression. When setting their price $P_{m t}(i)$, intermediate goods importers face a demand given by $x_{t}^{\mathrm{M}}(i)$ and adjustment costs using parameters $\xi_{m}$ and $\pi_{m}$.

\subsection{The household}

There exists a unit mass continuum of households, indexed by $j \in[0,1]$. The preferences of household $j$ are given by (expected discounted sum of utility functions $\left.U_{t}\left(c_{t}(j), h_{t}(j)\right)\right)$

$$
\mathbb{E}_{t} \sum_{\tau=0}^{\infty} \beta^{\tau}\left[\frac{v^{c}}{1-\sigma_{c}} c_{t+\tau}(j)^{1-\sigma_{c}}-\frac{v^{h}}{1+\sigma_{h}} h_{t+\tau}(j)^{1+\sigma_{h}}\right]
$$

where $0<\beta<1$ is a constant discount factor, $c_{t}(j)$ denotes the domestic consumption bundle, and $h_{t}(j)$ is the quantity of hours supplied by household of type $j . v^{c}$ and $v^{h}$ are constants and $\sigma_{c}$ and $\sigma_{h}$ parameters characterizing the preferences.

\footnotetext{
${ }^{5}$ See the next section for the calculation of the discount factors.
} 
In each period, the representative household $j$ faces a budget constraint

$$
\begin{aligned}
& P_{t}\left(\left(1+\eta_{t}(j)\right) c_{t}(j)+i_{t}(j)+\frac{\xi_{w}}{2}\left(\frac{W_{t}(j)}{W_{t-1}(j)}-\pi_{w}\right)^{2} y_{t}\right) \\
& \quad+B_{t+1}^{\mathrm{D}}(j)+s_{t} B_{t+1}^{\mathrm{F}}(j)+M_{t}(j)=R_{t-1} B_{t}^{\mathrm{D}}(j)+R_{t-1}^{\mathrm{F}} s_{t} B_{t}^{\mathrm{F}}(j) \\
& \quad+M_{t-1}(j)+P_{t} z_{t} k_{t}(j)+W_{t}(j) h_{t}(j)+N_{t}(j)+\Pi_{t}(j)
\end{aligned}
$$

where $B_{t}^{\mathrm{D}}(j)$ and $B_{t}^{\mathrm{F}}(j)$ are domestic and foreign currency bonds, $R_{t}$ and $R_{t}^{\mathrm{F}}$ are gross interest rates on domestic and foreign bonds, $i_{t}(j)$ is investment expenditure, and $k_{t}(j)$ is the amount of physical capital owned by the household and leased to the firms at the real rental rate $z_{t} . M_{t-1}(j)$ is the amount of money that the household brings into period $t, M_{t}(j)$ is the end of period $t$ money, and $N_{t}(j)$ is a nominal lump-sum transfer received from the monetary authorities. $\Pi_{t}(j)$ denotes the profits distributed to the household by the firms. The expression $\frac{\xi_{w}}{2}\left(\frac{W_{t}(j)}{W_{t-1}(j)}-\pi_{w}\right)^{2} P_{t} y_{t}$ captures the cost of adjusting nominal wages in terms of final good consumption, where $\pi_{w}$ is the steady-state rate of wage inflation. $\eta\left(v_{t}(j), \zeta_{t}\right)$ is a proportional monetary transaction cost that depends on the household's money velocity $v_{t}(j)=\frac{P_{t} c_{t}(j)}{M_{t}(j)}$ and on a money demand shock $\zeta_{t}$, whose properties are defined in the next section. For this monetary distortion, we use the function $\eta($.$) with parameters A$ and $B$ borrowed from Schmitt-Grohé and Uribe (2004),

$$
\eta\left(v_{t}(j), \zeta_{t}\right)=\zeta_{t}\left(A v_{t}(j)+\frac{B}{v_{t}(j)}-2 \sqrt{A B}\right) .
$$

Capital accumulates according to the law of motion

$$
k_{t+1}(j)=i_{t}(j)-\frac{\varphi}{2}\left(\frac{i_{t}(j)}{k_{t}(j)}-\kappa\right)^{2} k_{t}(j)+(1-\delta) k_{t}(j)
$$

where $\delta \in[0,1]$ denotes the rate of depreciation. $\kappa>0$ is a constant term such that capital adjustment costs are nil in steady state. $\varphi$ is an adjustment cost parameter.

The household then determines consumption/saving and money holdings decisions maximizing Eq. 13 subject to Eqs. 14 and 16 where $\Lambda_{t}(j)$ and $\Lambda_{t}^{k}(j)$ are the Lagrange multipliers associated with both constraints. This leads to the following set of optimality conditions:

$$
\begin{aligned}
v^{c} c_{t}(j)^{-\sigma_{c}}=\Lambda_{t}(j) P_{t} & {\left[1+2 \zeta_{t}\left(A v_{t}(j)-\sqrt{A B}\right)\right], } \\
\beta \mathbb{E}_{t} \frac{\Lambda_{t+1}(j)}{\Lambda_{t}(j)} & =1-\zeta_{t}\left(A v_{t}(j)^{2}-B\right), \\
\frac{1}{R_{t}} & =\beta \mathbb{E}_{t} \frac{\Lambda_{t+1}(j)}{\Lambda_{t}(j)}
\end{aligned}
$$




$$
\begin{gathered}
\frac{1}{R_{t}^{\mathrm{F}}}=\beta \mathbb{E}_{t}\left(\frac{\Lambda_{t+1}(j)}{\Lambda_{t}(j)} \frac{s_{t+1}}{s_{t}}\right) \\
\Lambda_{t}(j) P_{t}=\Lambda_{t}^{k}(j)\left(1-\varphi\left(\frac{i_{t}(j)}{k_{t}(j)}-\kappa\right)\right), \text { and } \\
\Lambda_{t}^{k}(j)=\beta \mathbb{E}_{t}\left[\Lambda_{t+1}(j) P_{t+1} z_{t+1}+\Lambda_{t+1}^{k}(j)\left(\frac{\varphi}{2}\left(\frac{i_{t+1}(j)^{2}}{k_{t+1}(j)^{2}}-\kappa^{2}\right)+1-\delta\right)\right] .
\end{gathered}
$$

The workers have monopoly power when selling their labor services. The first-order optimal condition with regard to the choice of the nominal wage rate, $W_{t}(j)$, is obtained by maximizing Eq. 13 subject to Eq. 14 and the total demand for type $j$ labor $h_{t}(j)=\int_{0}^{1} h_{t}(i, j) \mathrm{d} i$ and is given by

$$
W_{t}(j)=\frac{1}{\vartheta}\left(\frac{v^{h} h_{t}(j)^{\sigma_{h}}}{\Lambda_{t}(j)}+\frac{\vartheta-1}{h_{t}(j)}\left[\begin{array}{c}
\frac{W_{t}(j)}{W_{t-1}(j)} \xi_{w}\left(\frac{W_{t}(j)}{W_{t-1}(j)}-\pi_{w}\right) P_{t} y_{t}- \\
\mathbb{E}_{t} D_{t, t+1} \frac{W_{t+1}(j)}{W_{t}(j)} \xi_{w}\left(\frac{W_{t+1}(j)}{W_{t}(j)}-\pi_{w}\right) P_{t+1} y_{t+1}
\end{array}\right]\right) .
$$

\subsection{Market clearing conditions}

Foreigners do not hold any domestic bonds so $B_{t}^{\mathrm{D}}(j)=0$ for all $t$. The interest rate on foreign liabilities $R^{\mathrm{F}}$-in real terms using foreign inflation $\pi^{\star}$-carries a risk premium with respect to the world nominal interest rate $R^{\star}$ according to

$$
\frac{R_{t}^{\mathrm{F}}}{\pi^{\star}}=\frac{R_{t}^{\star}}{\pi^{\star}}-\varrho\left(\frac{B_{t+1}^{\mathrm{F}}}{P_{t}^{\star}}\right)
$$

where the expression $\varrho\left(\frac{B_{t+1}^{\mathrm{F}}}{P_{t}^{\star}}\right)$ is strictly increasing in the aggregate level of real foreign debt. $R_{t}^{\star}$ is assumed to be an exogenous stochastic process that is defined in the next section.

\subsection{Monetary policy}

We study two international monetary arrangements: A flexible system and a unilateral peg. In the latter case, the monetary authorities in the small open economy keep the nominal exchange rate vis a vis the rest of the world perfectly constant. 
Under a flexible exchange rate system, monetary policy can be conducted without any reference to the exchange rate. Henceforth, we consider two different rules:

a) A standard ${ }^{6}$ HMT rule

$$
R_{t}=k_{\pi}\left(\pi_{t}-\pi\right)+k_{y}\left(y_{t}-y\right),
$$

b) Perfect CPI inflation targeting ${ }^{7}$ (IT),

where $R_{t}$ is the nominal interest rate, $\pi_{t}$ is the inflation rate of the general price index, $\pi$ is the inflation target (equal to the steady-state rate of inflation), $y_{t}$ is output and $y$ is the output target (equal to the steady-state value of output).

The motivation for restricting attention to these simple rules is purely practical. We believe that the conduct of monetary policy is limited by severe informational problems that prevent policymakers from computing globally 'optimal' policies and using the flexible price or the efficient level of output as their policy target.

\section{Calibration}

We are mostly interested in establishing results that hold for a 'generic' rather than for a particular, real life economy. ${ }^{8}$ Hence, to illustrate our case for flexible exchange rates, we rely mostly on parameters that are commonly used in the open economy literature. The benchmark calibration is reported in Table 1.

\subsection{Parameters}

There is not much information in the literature regarding the appropriate range of values for the parameters of nominal prices $\left(\xi_{x}, \xi_{m}\right)$ and wage adjustment costs $\left(\xi_{w}\right)$. Following Hairault and Portier (1993), we use a value of 1 in the benchmark case but vary it in the experiments run when studying the effects of asymmetries in price rigidity across sectors (where we use a value of 10). Note that a value of 1 means that changing the inflation rate by $1 \%$ (0.01) from its steady-state value entails an output cost of $0.005 \%$ of GDP.

$\rho$ is set equal to 0.8 so that the elasticity of substitution between foreign and domestic goods is quite high (as befits a small open economy). $\omega$ is set such that the import share in the economy is $15 \%$. The depreciation rate $\delta$ is set to $2.5 \%$. The capital adjustment cost parameter $\varphi$ is set to 10. Both elasticities $\theta$ and

\footnotetext{
${ }^{6} \mathrm{We}$ could easily include an exchange rate targeting term in the policy rule. As mentioned earlier, little would be learned from this specification as a managed float with the degree of flexibility (targeting) chosen appropriately would always weakly dominate the two limiting regimes, that is, the perfectly flexible and the perfectly fixed.

${ }^{7}$ This procedure is implemented by assuming $k_{y}=0$ and a suitably large value for $k_{\pi}$.

${ }^{8}$ See Cuche-Curti et al. (2009), for an application to the Swiss economy.
} 
Table 1 Parameter calibration-benchmark case

\begin{tabular}{lllllr}
\hline Parameter & & Value & Parameter & Value \\
\hline Trade elasticity & $\rho$ & 0.8000 & Imported inflation rate & $\pi_{m}$ & 1.0096 \\
Trade share & $\omega$ & 0.8500 & Wage inflation & $\pi_{w}$ & 1.0096 \\
Foreign domestic production & $\omega^{\star}$ & 0.9634 & Discount factor & $\beta$ & 0.9900 \\
Production, int. goods, capital share & $\alpha_{k}$ & 0.2268 & Preferences, consumption & $\nu^{c}$ & 1.0000 \\
Production, int. goods, labor share & $\alpha_{h}$ & 0.7732 & Preferences, labor & $\nu^{h}$ & 8.4342 \\
Real distortion, good markup & $\theta$ & 0.8000 & Preferences, consumption & $\sigma_{c}$ & 1.5000 \\
Real distortion, wage markup & $\vartheta$ & 0.8000 & Preferences, labor & $\sigma_{h}$ & 1.0000 \\
Marginal cost parameter & $\varsigma$ & 0.5854 & Monetary distortion & $A$ & 0.0111 \\
Nominal rigidity, int. goods & $\xi_{x}$ & 1.0000 & Monetary distortion & $B$ & 0.0752 \\
Nominal rigidity, imports & $\xi_{m}$ & 1.0000 & Depreciation & $\delta$ & 0.0250 \\
Nominal rigidity, wage & $\xi_{w}$ & 1.0000 & Capital adjustment cost & $\varphi$ & 10.0000 \\
Overall inflation rate & $\pi$ & 1.0096 & Capital adjustment cost & $\kappa$ & 0.0250 \\
Domestic inflation rate & $\pi_{x}$ & 1.0096 & Financial risk premium & $\varrho$ & 0.0200 \\
HMT rule, inflation reaction & $k_{\pi}$ & 1.5000 & HMT rule, output reaction & $k_{y}$ & 0.5000 \\
\hline
\end{tabular}

Notes: int. goods = intermediate goods; the calibration of the HMT feedback rule corresponds to the one use in the HMT strategy; these coefficients are set to zero $\left(k_{y}\right)$ and to a suitably large value $\left(k_{\pi}\right)$ in the case of a strict inflation targeting strategy; per construction, they are absent in the case of a fixed regime

$\vartheta$ are set such that markups in the economy are $25 \%$. $\alpha_{k}$, the elasticity of the production function to physical capital, is set such that the labor share in the economy is 0.6. $\sigma_{c}$ and $\sigma_{h}$, the coefficients of risk aversion in consumption and labor supply elasticity, are set to 1.5 and 1 , respectively. $v^{h}$ is set in order for the model to generate a total fraction of time devoted to market activities of $31 \%$ at the steady state. The discount factor $\beta$ takes a value such that households discount the future at an annual rate of about $4 \%$. Steady-state inflation rates are set to an annual value of $3.9 \%$.

\subsection{Stochastic processes and steady states}

All shocks are assumed to follow independent AR(1) processes with an autoregressive coefficient of 0.9. In the benchmark case, the standard deviation of all shocks has been set to 0.004 . The steady-state values of shocks call for the following comments. Money demand $\zeta$ and productivity $\mathcal{A}$ shocks have steadystate values implying that they do not play any role at the steady state. World output $y^{\star}$ is ten times bigger than domestic output $y$ at the steady state. The steady-state value of the world interest rate $R^{\star}$ is set at 1.0198 and the one of the real exchange rate $s P^{\star} / P$ at 0.8077 . The steady-state value of the foreign interest rate $R^{\mathrm{F}}$ is equal to the one of the world interest rate, because $B^{\mathrm{F}}$ is assumed to be zero at the steady state.

\section{The results}

After computing the deterministic steady state we take a second-order log approximation around it. Welfare is computed using a quadratic approximation 
Table 2 Welfare under real and monetary distortions

\begin{tabular}{llll}
\hline Exchange rate regime & Flexible HMT & Flexible IT & Fixed \\
\hline Real & $\mathbf{- 3 3 7 . 3 0 7 5}$ & -337.3088 & -337.3091 \\
Monetary & -228.1326 & -228.1177 & $\mathbf{- 2 2 8 . 1 1 1 0}$ \\
Real + monetary & -337.1003 & -337.0853 & $\mathbf{- 3 3 7 . 0 7 5 1}$ \\
\hline
\end{tabular}

Notes: Values for all price frictions are set to 1 ; all shocks included; standard deviation of all shocks set to 0.004. IT is perfect inflation targeting and HMT is the standard interest rate rule

The number(s) in bold signifies the regime with the highest welfare performance

to the utility function around the efficient equilibrium as described by Woodford (2003), and Collard and Dellas (2005). The welfare results are reported in Tables 2 and 3 .

\subsection{Impact of real and monetary distortions}

In order to have some idea of the relative importance of the real and monetary distortions we start by reporting welfare for the case of real distortions only (that is, those associated with imperfect competition) and the case with both real distortions and the benchmark monetary distortion (Table 2). In the former case, the monetary arrangement in place is of no consequence. As can be seen (at least in the benchmark case) real distortions matter much more than nominal ones.

\subsection{Impact of price and wage rigidities}

In Table 3 we report welfare levels for each individual shock (i.e. setting the standard deviation of that shock to 0.01 and that of all other shocks to 0 ) as we vary the relative importance of a particular nominal friction (keeping the level of monetary and real distortions fixed as in the benchmark case).

Table 3 Welfare comparison under various nominal rigidities

\begin{tabular}{lllll}
\hline Shocks & Frictions & HMT & IT & Fixed \\
\hline Supply $\mathcal{A}$ & $\xi_{w}$ & -337.5816 & -337.2649 & $-\mathbf{3 3 7 . 2 3 2 1}$ \\
& $\xi_{x}$ & -337.5733 & $\mathbf{- 3 3 7 . 2 2 1 9}$ & -337.2598 \\
Money demand $\zeta$ & $\xi_{w}$ & $-\mathbf{3 3 7 . 2 3 9 2}$ & $\mathbf{- 3 3 7 . 2 3 9 2}$ & $\mathbf{- 3 3 7 . 2 3 9 2}$ \\
& $\xi_{x}$ & $-\mathbf{3 3 7 . 2 3 9 2}$ & $\mathbf{- 3 3 7 . 2 3 9 2}$ & $\mathbf{- 3 3 7 . 2 3 9 2}$ \\
Foreign price $p^{\star}$ & $\xi_{w}$ & -342.2528 & $\mathbf{- 3 3 7 . 0 1 3 8}$ & -338.5040 \\
& $\xi_{x}$ & -342.8822 & $\mathbf{- 3 3 6 . 9 4 6 5}$ & -338.8304 \\
Foreign demand $y^{\star}$ & $\xi_{w}$ & -337.2374 & $\mathbf{- 3 3 7 . 2 3 2 2}$ & -337.2450 \\
& $\xi_{x}$ & -337.2395 & $\mathbf{- 3 3 7 . 2 3 2 2}$ & -337.2470 \\
Foreign interest rate $R^{\star}$ & $\xi_{w}$ & -352.7135 & $\mathbf{- 3 3 6 . 7 0 0 2}$ & -337.8990 \\
& $\xi_{x}$ & -354.0385 & $\mathbf{- 3 3 6 . 6 8 5 8}$ & -338.2327 \\
\hline
\end{tabular}

Notes: Real and monetary distortions are included; the value for the considered nominal friction is set to 10 and the value for the other nominal frictions is set to 1 ; the standard deviation of the shock is $0.01 ; p^{\star}=\frac{s P^{\star}}{P}$; IT is perfect inflation targeting, HMT is the standard interest rate rule, and 'Fixed' assumes a fixed exchange rate regime

The number(s) in bold signifies the regime with the highest welfare performance 
Several patterns can be seen in these tables. The welfare rankings of alternative regimes vary as a function of the type of shock, the relative importance of individual sources of nominal rigidity and the type of monetary policy pursued.

For foreign shocks, welfare is higher under a flexible exchange rate system as long as monetary policy targets the inflation rate strictly. Moreover, this is independent of the source of nominal rigidity. Interestingly, the flexible exchange rate regime under the popular HMT interest rate rule does not fare as well as a peg. For money demand shocks, the choice of the regime does not matter much. The picture is more fuzzy in the case of domestic supply shocks. Here, the flexible regime and strict inflation targeting perform better only when the main source of nominal rigidity is in the goods markets. In the case of dominant labor market rigidity, the pegged regime fares better.

That a flexible exchange rate regime with strict inflation targeting would fare well under supply shocks and in the presence of significant domestic price rigidity in the goods markets is not surprising, this is the standard case considered in the literature. It is true that most of this literature uses specifications in which the flexible price equilibrium is efficient, which automatically makes strict inflation targeting (and hence a flexible exchange rate system) the globally optimal policy. Nevertheless, as Collard and Dellas (2005), show in a closed economy, a strong case for price stability remains even when the flexible price equilibrium is not efficient. Our results indicate that this result generalizes to the open economy. Similarly, the result that strict inflation targeting would not fare as well under supply shocks and wage rigidities is not surprising.

Nonetheless, the novelty of our analysis lies in the following two findings. First, that nominal wage rigidity supports a fixed over a flexible regime in the case of supply shocks, but it works in favor of a flexible exchange rate regime in the case of external shocks. And second, that inflation targeting suffices to make a system of flexible exchange rates superior under all types of external shocks independent of the source of nominal rigidity.

The intuition for the poor performance of an activistic, flexible regime in the case of supply shocks under wage stickiness can be understood as follows. In the efficient economy, the response of inflation to a supply shock tends to be small (in our model). This implies that the increase in the real wage following a positive supply shock is accomplished mostly via an increase in nominal wages. When it is costly to adjust the nominal wage, then there is a need for a larger drop in domestic goods prices in order to support the efficient increase in real wages. Under inflation targeting, prices are prevented from dropping, so the real wage is too low, and the increase in output and employment too high relative to the efficient response. Under a peg, on the other hand, exchange rate stabilization requires contractionary policy (because a positive domestic supply shock leads to a domestic currency depreciation as part of the required home terms of trade deterioration) which contributes to lower domestic goods prices.

Similar arguments can be used to compare alternative monetary policies in the case of external shocks. Consider, for instance, a situation with nominal 
wage rigidity and foreign output shocks. An increase in world output increases the demand for the domestic intermediate goods. The domestic terms of trade improve, via a combination of a more expensive domestic goods, less expensive imported goods, and a stronger domestic currency. The demand for domestic labor increases, pushing the real wage up, which is accomplished partly through an increase in the nominal wage. Were the nominal wage sticky, the required real wage increase would need a smaller increase in domestic goods prices relative to that in the efficient economy. Under inflation targeting, the effect of the foreign output shock on domestic inflation is quite small, and thus monetary policy does not need to respond much in order to stabilize the inflation rate. Under a money targeting policy, the money supply does not respond at all as the effect of the foreign shock on the exchange rate is relatively strong (domestic currency appreciation). In order to counter this appreciation, looser monetary policy is called for, which leads to higher domestic goods prices. Hence, under a peg prices are moved in the wrong direction, which undermines its performance.

\subsection{Caveats}

There are several issues that the paper abstracts from, some of which could be the subject of future research. First, fixed regimes tend to be associated with - costly-speculative attacks, currency crises and devaluations, a fact that gives an indirect advantage to the flexible exchange rate system. We could in principle incorporate an exogenous probability of a devaluation, conditional on some development in the economy. We have decided against doing so because our objective is to evaluate the role played by price sluggishness in the optimal choice of the exchange rate system, rather than carry out an exhaustive study of benefits and costs associated with alternative regimes.

Second, the exchange rate in our model is determined fully by fundamentals. If some (perhaps much) of the volatility of the exchange rate, however, came from non-fundamental sources, a flexible regime would be associated with excessive volatility and its performance would be compromised. There has not been much progress in modeling these types of effects in the literature, though, so we do not feel that we can incorporate them in a non-controversial way.

\section{Conclusions}

The new macroeconomic models have provided a rigorous and empirically relevant framework for the study of the properties and implications of monetary arrangements, both domestic and international. In this paper we use a more general model of a small open economy, namely a model that includes several nominal and real frictions, to evaluate alternative exchange rate regimes. We find that the strong support for flexible exchange rate systems claimed in the literature reflects, to some degree, certain assumptions about the source of nominal rigidity and the type of shock. Nonetheless, a case for flexible 
exchange rates can still be made as long as monetary policy aims strongly at inflation stability and the shocks originate mostly from abroad.

Another lesson that emerges from our analysis is that adhering to a standard nominal interest rate rule (such as the HMT rule) and ignoring movements in the exchange rate may not be a good idea. In most of the cases considered, such a policy is dominated by one that simply targets strictly the exchange rate. In order for a country to take advantage of the benefits associated with a flexible exchange rate regime it must accompany this choice with a policy of strict inflation targeting.

Acknowledgements We thank Patrick Fuchs, Marcel Savioz, and Alan Stockman for valuable comments and discussions. The views expressed are solely the responsibility of the authors and should not be interpreted as reflecting the views of their affiliations or of any other person associated with them.

\section{References}

Backus D, Kehoe P, Kydland F (1995) International business cycle: theory and evidence. In: Cooley T (ed) Frontiers of business cycle research. Princeton University Press, Princeton, pp 331-356

Canzoneri M, Cumby R, Diba B (2003) Recent developments in the macroeconomic stabilization literature: is price stability a good stabilization strategy? In: Altug S et al (ed) Dynamic macroeconomic analysis, theory and policy in general equilibrium. Cambridge University Press, Cambridge, pp 212-242

Collard F, Dellas H (2002) Exchange rate systems and macroeconomic stability. J Monet Econ 49(3):571-599

Collard F, Dellas H (2005) Tax distortions and the case for price stability. J Monet Econ 52(1): 249-273

Cuche-Curti N, Dellas H, Natal J-M (2009) DSGE-CH: a dynamic stochastic general equilibrium model for Switzerland. Economic Studies 2009-5, Swiss National Bank

Dellas H (2006) Monetary policy in open economies. Eur Econ Rev 50(6):1471-1486

Duarte M (2003) Why don't macroeconomic quantities respond to the exchange rate variability? J Monet Econ 50(4):889-913

Friedman M (1953) The case for flexible exchange rates. In: Friedman M (ed) Essays in positive economics. University of Chicago Press, Chicago, pp 157-203

Hairault J-O, Portier F (1993) Money, new Keynesian macroeconomics, and the business cycle. Eur Econ Rev 37(8):1533-1568

Kollmann R (2002) Monetary policy rules in the open economy: effects on welfare and business cycles. J Monet Econ 49(5):989-1015

Ohanian L, Stockman A (1994) Short-run effects of money when prices are sticky. Federal Reserve Bank of Richmond Economic Quarterly 80(3):1-23

Pappa E (2004) Do the ECB and the FED really need to cooperate? Optimal monetary policy in a two-country world. J Monet Econ 51(4):753-779

Poole W (1970) Optimal choice of monetary policy instruments in a simple stochastic macro model. Q J Econ 84(2):197-216

Schmitt-Grohé S, Uribe M (2004) Optimal fiscal and monetary policy under sticky prices. J Econ Theory 114(2):198-230

Woodford M (2003) Interest and prices: foundations of a theory of monetary policy. Princeton University Press, Princeton 